\title{
Information Use and Mobile Devices: A Study Amongst Library Users of Selected Medical Faculties in Sri Lanka
}

\section{T. Ramanan ${ }^{1}$ \\ S. Santharooban ${ }^{2}$}

\begin{abstract}
A preliminary study was carried out as an initiative to probe into the possibilities of incorporating mobile apps and social networks in medical library services. Major objective was to find out the trend and preference of medical faculty students in using mobile devices for accessing information. The cross-sectional survey design was used with mixed method. Self-administered questionnaire was distributed among students of eight medical faculties in Sri Lanka and 120 filled questionnaires were received from six medical faculties. Data were analyzed using descriptive statistics and factor analysis. The use of a mobile device was analyzed through factor analysis. Cronbach's alpha of the particular statements is 0.864 which indicate the adequate internal consistency of the statements and Kaiser-Meyer-Olkin Measure of Sampling Adequacy (KMO) and Bartlett test value is 0.788 which indicate that the data is suitable for factor analysis. The factor analysis resulted in four-factor model, which explain $66.43 \%$ of variance in the data. The four factors are 'educational use', 'entertainment use', 'basic communicational use' and 'free call use'. Since the factor - educational use explain highest percentage (39\%) of variance in the data, it indicates that there is a potential to use mobile device for educational purposes. The results also have revealed that majority of the students $(85.2 \%)$ retrieved medical information through web resources using mobile devices. They also collect information using personal communication especially from friends and lecturers (41.5\%). Among the information sources which they use through the mobile devices, Google is at the first place $(82.3 \%)$ and Wikipedia $(80 \%)$ is in second place. Only $67.2 \%$ of them use the mobile device to read e-books. In the purpose of using mobile devices for educational purpose, highest usage was observed for retrieval of images $(81.8 \%)$, information on drugs (76.6\%) and clinical guidelines (72.3\%). Slow Internet connectivity $(77.9 \%)$, poor network or signal coverage $(76.6 \%)$, and lack of Wi-Fi facilities in faculty settings $(55.9 \%)$ are the major barriers to using of mobile devices. Despite the students are positive about mobile devices, they consider more about the authenticity of online information and lack of knowledge and awareness on access to medical information. Moreover, they were mostly inclined to Google and Wikipedia but were unaware of other online resources to access medical information. Therefore, adopting mobile devices in health/medical information literacy programmes and curricula are recommended with further research.
\end{abstract}

(C) (9) $\begin{aligned} & \text { This work is licensed under a Creative Commons Attribution- Share } \\ & \text { Alike } 4.0 \text { International License. }\end{aligned}$

${ }^{1}$ Former Senior Assistant Librarian, Eastern University, Sri Lanka. Image/Digitization Team, Access Information Inc., Etobicoke ON, Canada. Email: ramanan_6@yahoo.com, ORCID: https://orcid.org/0000-0003-1344-843X

2 Senior Assistant Librarian, Faculty of Health-Care Sciences, Eastern University, Sri Lanka Email: santharoobans@esn.ac.lk, iD https://orcid.org/0000-0003-1984-875X 
Keywords: Mobile Devices, Health Information Literacy, Mobile Apps, Social Networks, Medical Faculties

\section{Introduction}

Regardless of the kind of people, their searching for information and knowledge have been transformed in the recent past due to the wide and easy accessibility of information (De-Arteaga et al., 2015). Gradual increase in the economy has increased the use of ICT in almost all the sectors and by every individual. Among different facets of the advancement of ICT, smart mobile phones bring information to the palm of its owner.

Distinction between hand-held devices, especially smart mobile phones, and traditional computers are becoming blurred these days, as mobile devices enable their users with a wide spectrum of applications and networks (Lepp, Barkley, \& Karpinski, 2014). Since, smartphones and other modern mobile devices can function as personal computers it is easier for the users to perform computer-based tasks at their convenience (Ye, 2010).

The notion of the popularity of mobile devices is centred on versatility and portability, which made them essential organs of human life. In Sri Lanka, as Liyanage (2015) states that the use of mobile device/phone has even exceeded the population size, which indicates many individuals have multiple devices. Social networks, on the other hand, are on the rise in many sectors, which is triggered by the use of different mobile devices.

In an analysis, it was found that health/fitness sector is leading in using smartphones to tap information. Meanwhile, in certain other sectors such as trade and marketing, technology and government/law, people prefer tablets (Verto Analytics, 2017). These data evince the inevitable participation of mobile devices used for sharing and retrieving of information in active sectors, where medical information is no exception.

In this path, exploitation of the Internet on mobile devices has paved the way to library services on digital platform. As Ye (2010) says the information services are made possible on mobile phones that would lead to 'Mobile Phone Libraries.' The author further quotes in the article, this has enabled libraries to send out overdue notices and information alerts through SMSs and email apps. Moreover, students benefit from searching across the catalogue records and seeking answers to their queries placed to the librarians.

According to Taradi et al. (2016), it is reported that conventional teaching methods are time-limited thus unable to share more information and knowledge when required at unusual circumstances. This is where the need and use of mobile devices to help access the needed resources come in to focus. 
On contrary the benefits of using mobile devices, there are some adverse effects found by their use. A study has found in medical college that students extensively use their mobile devices for texting, listening to music, taking photographs, and browsing the Internet (Dixit et al., 2010). The findings revealed that mobile phone users become anxious when their devices stop functioning for a while. According to the research by Lepp et al. (2014), use of mobile phone has negative impacts on students' performance in studies, emotional wellbeing, and happiness.

In this regard, it is essential to learn whether the application of mobile technologies, social networks and library services could be integrated to improve the use of medical information. Therefore, this baseline survey was carried out to embark on a largescaled research to devise an appropriate medical-information literacy service model in medical faculties in Sri Lanka.

\section{Problem Statement and Objective}

With the increased use of mobile devices with the Internet connection, it has been a question as to what extent these devices are being used for getting the information by medical faculty students. Thus, the objective covers the purpose of using mobile devices, types of information on medical disciplines being tapped, and opinions and suggestions from the respondents.

\section{Method}

This preliminary study, targeting an experimental group of medical students, employed survey method which was executed with the administration of selfadministered questionnaires consisted on semi-structured questions. Data was collected among students of six medical faculties which Eastern University, Sri Lanka, University of Jaffna, Rajarata University of Sri Lanka, University of Kelaniya, University of Sri Jayawardenepura and the University of Peradeniya. The questionnaires were distributed among students at respective libraries of those medical faculties through convenient sampling with the support of library staff. The study targets one hundred and fifty (150) sample as it is a preliminary study and however, the one hundred and twenty (120) filled questionnaires were obtained from six medical faculties.

Since this was a preliminary study, the data were analysed mainly using qualitative method as the opinions of the subjects are more important to infer on, although the study focused on mixed method of analysis. The descriptive statistics were mainly used to analyse the quantitative responses, and, in addition, the exploratory factor analysis was used to group the responses for the use of different applications on mobile phones.

\section{Results and Discussion}

The total number of participants was 120 MBBS students randomly selected from all academic years. This body of the sample consisted of $73.5 \%$ of females and $26.5 \%$ 
of males. The majority of the students have smartphones and mobile devices like tablet and iPad, with the Internet connection.

\subsection{Types of applications used by medical students}

The types of applications on mobile devices used by students for different purposes were rated on five points Likert Scale. The reliability was analyzed through Cronbach's alpha and the alpha value was 0.864 , which shows that internal consistency was adequate. The suitability of data for factor analysis was tested through KMO (Kaiser-Meyer-Olkin Measure of Sampling Adequacy) and Bartlett test of sphericity. The value is 0.788 , which shows that the data is adequate for factor analysis. The factor analysis was done by using principal component method with Quartimax Rotation. This results in four-factor model, which can explain $66.43 \%$ of variance in the data. This model categorizes the experimental subjects based on the applications that they use.

The first factor has grouped those who used six applications and it can be named as 'educational use'. This factor explains around 39\% of the variance in data and these students use the mobile devices mostly for learning purposes such as e-book reading, online learning, research purposes as well watching movies and social networking. All the elements, except social networking, in this factor, have highest factor loadings. Since this factor explains the percentage of variance in the data compared to other factors, there is a potential to use the mobile applications for educational purposes among the medical students. The students who come under this group can easily be trained further to access the health-information using mobile devices. Moreover, as social network use also included in this factor, social networks have a potentiality to be used in disseminating medical related information resources.

On the other hand, factor 2 , which exerts only $11 \%$ of the variance, has grouped the subjects that use the mobile devices for entertainment purposes and this factor be named as 'entertainment use' factor 3 explains only $9 \%$ of the variance and indicates those who use the mobile devices for basic communication such as SMS and voice calls and this factor can be named as 'basic communicational use'. Finally, factor 4 denotes the ones that use the mobile devices for free call and photography and explain only $7 \%$ of the variance in the data and this factor can be named as 'free call use' (Table 1). 
Table 1: Factor analysis of the types of mobile application

\begin{tabular}{|c|c|c|c|c|}
\hline & \multicolumn{4}{|c|}{ Factors } \\
\hline & 1 & 2 & 3 & 4 \\
\hline Reading e-books and/ or articles & .912 & & & \\
\hline $\begin{array}{l}\text { Learning online (e.g. iCloud, Distance Education, } \\
\text { cloud learning etc.) }\end{array}$ & .807 & & & \\
\hline $\begin{array}{l}\text { Internet browsers (e.g. Google Chrome, Internet } \\
\text { Explorer, Mozilla Firefox, etc.) }\end{array}$ & .799 & & & \\
\hline Doing research/ academic activities/presentations & 776 & & & \\
\hline Movies/videos & .758 & & & \\
\hline $\begin{array}{l}\text { Keeping touch with social network notifications (e.g. } \\
\text { Face Book, Twitter, LinkedIn, etc.) } \\
\text { News feed (e.g. Weather/ Politics/Sports/etc.) }\end{array}$ & .550 & .796 & & \\
\hline $\begin{array}{l}\text { Chat apps (e.g. WhatsApp, Facebook Messenger, } \\
\text { Google Chat, etc.) } \\
\text { Games (e.g. Action. Strategic, etc.) }\end{array}$ & & .638 & & \\
\hline Games (e.g. Action, Strategic, etc.) & & .588 & & \\
\hline Travel (e.g. Navigation, Google Maps/ Earth) & & .561 & & \\
\hline Text messages (SMS) & & & .870 & \\
\hline Voice Call & & & .698 & \\
\hline Free call applications (e.g. Skype/Viber/etc.) & & & & .541 \\
\hline Photography & & & & .538 \\
\hline
\end{tabular}

According to the analysis presented in Table 1, students who are more inclined to use their mobile phones to tap medical information. This evinces the convenience and versatility of mobile devices being used at work or study, thus medical students need to be catered with information services that engage mobile phones and their apps.

\subsection{Mode of retrieval of medical information by using mobile devices}

There are two categories broadly which students use to receive information, namely the Internet and regular communication. As in the first category, majority of the students $(85.2 \%)$ retrieve medical information through web resources using mobile devices, where $41.5 \%$ of them receive this information through personal communication such as email. Whereas, in the second category, majority of the students get the medical information from friends $(86.2 \%)$, then from lecturers (39.2\%) and next from consultant/doctors (38.9\%) (Table 2). 
Table 2: Mode of retrieval of medical information

\begin{tabular}{lr}
\hline Means of Retrieval & Percentage \\
\hline The Internet: & \\
Through web resources & 85.2 \\
Through personal communication & 41.5 \\
Through social networks & 26.4 \\
Through Skype or other chat facilities & 8.3 \\
Regular communication: & \\
Friends & 86.2 \\
Lecturers & 39.2 \\
Consultants/ Doctors & 38.9 \\
Nurses & 6.5 \\
Librarian & 0.0 \\
\hline
\end{tabular}

Web resources seen as important in providing medical information; however, the credibility and authenticity of these resources are also questioned by the students. This was indicated by students for open-ended questions which will be discussed later. Reliance on friends for getting information has shown the preference of intimacy when it comes to seeking for medical facts. Nevertheless, it has been found that no students approached their librarian for access medical information. Does this warn the librarians if not executing state-of-art services and strategies? Further research will address this issue.

\subsection{Types of medical information resources used by students}

There are many online resources that students use on mobile devices for learning and educational purposes. Majority of the respondents use Google $(82.3 \%)$ for browsing the information. It has also been found that around $80 \%$ of them use Wikipedia for educational purpose. Surprisingly, 67.2\% of them are e-book readers. Among the databases, $54.4 \%$ and $26.9 \%$ of students prefer Medline Plus and PubMed, respectively, while a considerable percentage of students uses HINARI. Few other databases are also used by students in surveyed medical faculties (Table 3).

Table 3: Online resources that students use through mobile devices

\begin{tabular}{ll|ll}
\hline Online resources & $\%$ & Online resources & $\%$ \\
\hline Google & 82.3 & HINARI & 6.6 \\
Wikipedia & 80.3 & PubMed Central & 3.2 \\
eBook & 67.2 & BioMed Central & 1.6 \\
MedlinePlus & 54.4 & INASP/ DOAJ & 1.6 \\
PubMed & 26.9 & SLJOL & 1.6 \\
Yahoo & 18.1 & & \\
\hline
\end{tabular}

The students also reported (in open-ended question) that they have access to journals such as Ceylon Medical Journal, New England Journal of Medicine (NEJM), British Medical Journal (BMJ), Lancet and the American Journal of Medicine, through mobile devices. Among the students whose university Library has OPAC only $21.8 \%$ 
of them access to the OPAC through online devices. In addition, few of them use Medscape, WebMd, UpToDate and drugs.com.

\subsection{Purposes of using mobile devices}

Use of mobile devices by medical students envelop a range of purposes (Table 4). The highest usage was observed for retrieval of images $(81.8 \%)$, followed by the information on drugs (76.6\%) and clinical guidelines (72.3\%). Substantial number of students $(60.6 \%)$ uses their mobile devices for making lecture notes either by recording or scribbling. Similar number of subjects $(60.6 \%)$ uses those devices for performing a differential diagnosis.

Table 4: Use of retrieving medical information through mobile devices

\begin{tabular}{ll}
\hline \multicolumn{1}{c}{ Purposes } & $\%$ \\
\hline 1. Retrieval of images & 81.8 \\
2. Access the information on drugs & 76.6 \\
3. Clinical guidelines & 72.3 \\
4. Online learning & 69.7 \\
5. Making Lecture Notes & 60.6 \\
6. Perform differential diagnosis & 60.6 \\
7. Accessing research articles & 52.3 \\
8. Clinical calculation & 46.9 \\
9. Point-of care information & 39.1 \\
\hline
\end{tabular}

Online learning $(69.7 \%)$, browsing the research articles $(52.3 \%)$, clinical calculation (46.9\%), and tapping the point-of-care information (39.1\%) are other purposes for which mobile devices are used by medical students.

\subsection{Obstacles to using mobile devices for getting information}

According to the results, major barriers to using mobile devices for getting information and learning are the weak network or signal coverage $(76.6 \%)$ and slow Internet connectivity (77.9\%), although these issues are on the side of service providers. Hence, the next major issue reported by the students is lack of Wi-Fi facilities in university/hospital/hostel $(55.9 \%)$. This can be improved by providing better Wi-Fi facilities at learning hubs to overcome those three major barriers (Table $5)$. 
Table 5: Challenges of using mobile devices for education purpose

\begin{tabular}{ll}
\hline \multicolumn{1}{c}{ Challenges } & $\%$ \\
\hline Slow Internet connection & 77.9 \\
Weak network/signal coverage & 76.5 \\
$\begin{array}{l}\text { No Wi-Fi facilities in } \\
\text { university/hospital/hostel }\end{array}$ & 55.9 \\
$\begin{array}{l}\text { Poor battery life } \\
\text { Lack of time }\end{array}$ & 54.4 \\
Mobile devices are expensive/ unaffordable & 44.1 \\
Complicated phone applications & 33.8 \\
Unable to read on small screens & 29.9 \\
$\begin{array}{l}\text { Not prefer to use my mobile at study } \\
\text { Don't know online information can be } \\
\text { obtained through mobile device }\end{array}$ & 25 \\
$\begin{array}{l}\text { Don't know how to operate mobile device } \\
\text { to get information }\end{array}$ & 13.2 \\
\hline
\end{tabular}

Other barriers are mainly personal which include financial and cognitive factors. Besides, lack of time (44.1\%) hinders the use of mobile devices for tapping medical information, which might imply that those respondents are using other means to get connected with information resources. Unaffordability of sophisticated devices (33.8\%) and being unable to rectify power issues with mobile devices $(54.4 \%)$ are connected to financial status of the subjects. Cognitive factors such as unaware of operation (7.4\%) and exploitation (10.4\%) of mobile devices to access the information resources are also set-backs to execute novel learning and information service activities. In addition, personal rules to not using mobile devices at study $(13.2 \%)$ is another challenging impediment to using online resources at extended times.

\section{Qualitative analysis of opinions on mobile devices for medical learning}

A comprehensive analysis of opinions recorded from students' response help understand the current trend and scenario with using mobile devices for learning at medical and health-care faculties. The statements of respondents were categorized as advantages, drawbacks, training needs and recommendations to make ease of understanding. The following figure was created as a mind-map to display the opinions expressed with regard to using mobile devices for learning in medical faculties: 


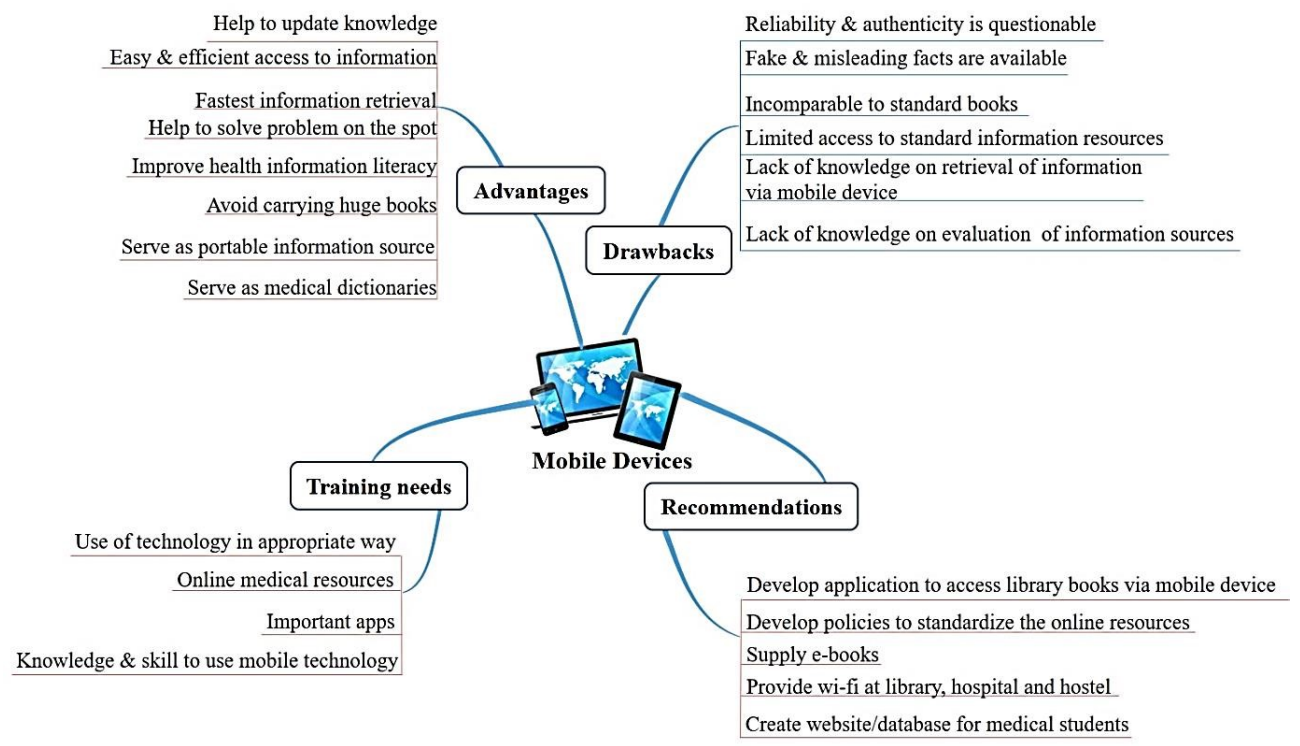

(within the chart use mobile devices and Wi-Fi facilities)

Figure 1: Mind-map of students' opinion on mobile devices to receive medical information

\subsection{Positive inclination towards the use of mobile devices}

Majority of students unanimously accepted that using mobile devices for getting medical information is "easy," "faster" and "convenient." Comparatively, information retrieved from mobile devices covers a range of sources including online dictionaries and encyclopaedias, which are vital in times of diagnosis and "problemsolving." As students state, instead of referring to a number of physical books, a mobile device with the Internet serves as a single gateway to various information resources.

More importantly, as one of the students points out that "it is very useful to understand basic information about any disease conditions before moving to complex information, especially it is useful to have a general idea when examining a patient." This clearly shows the role and position of mobile devices in medical information literacy programmes.

Further, "new research findings in the medical field through mobile devices" is "useful to improve medical information literacy" according to students' feedback. These statements strengthen the sustainable implementation of medical information literacy curriculum and programmes across the medical faculties in Sri Lanka.

\subsection{Need for facilities and training}

Since the use of information could not be limited and there are numerous unauthenticated resources, students insist on standards and policies set streamline and to ensure the authenticity of online resources. Their main concern is to install Wi-Fi routers to widen the free access to the Internet at faculties, libraries, and hostels. Many 
students cannot afford $24 / 7$ connectivity to the Internet, thus, lack of free Wi-Fi facilities would curtail the use of mobile devices for learning.

Students have admitted that they need training and instructions to use mobile devices as many of them are not technical savvy and experts. In addition, they need to be aware of appropriate information resources as it is difficult to identify credible sources on the Internet. This concern concentrates around developing unique mobile phone apps for each medical faculty with integrating resources and databases. Websites of these medical faculties are also to be improved. One of the drawbacks that they indicated is lack of knowledge on evaluation of website or online resources. This must be included in the training programme as well.

Moreover, the students also indicated they need to e-repository of library books as they report "develop application to access library books via mobile devices". Although this is much difficult task in librarians' point of view, this should be the solution to the near future. The libraries need to consider demanding or requesting book vendors to supply e-books as they purchase physical books.

\subsection{Controversial arguments against mobile devices use}

While embracing the benefits of using mobile devices one must be aware of its adverse effects in life. Many studies have been conducted to alarm the detrimental consequences of continuous use of handheld devices. Liyanage ( 2015) sheds his thoughts on pros and cons of using smartphones, which includes spending more time on these devices than on studies.

However, respondents' concerns were focused on the authenticity and trustworthiness of the online resources for medical information. Many of the subjects recorded that online resources are "unreliable" and giving "misleading medical facts." Moreover, "access is limited to reliable sources" as most of the medical databases require expensive institutional subscriptions.

Alleyne (2011) says "Some said they feel so bereft without their iPhone or Blackberry that it evokes similar feelings to the "phantom limb' syndrome suffered by amputees." She continues to say that young generation, which is seriously reliant on using mobile devices, has mental and physical symptoms of distress when they try to go unplugged for a full day. Surprisingly, students in this study expressed that "(using mobile devices) are incomparable with reading standard textbooks which are standard for all the time," which stress on the parallel use of traditional information resources in the medical information literacy programmes.

Another study carried out by Ramesh et al. (2018), focus on hygiene issues of using phones by medical students and staff while attending their patients. Considerable number of mobile phone users did not wash their hands after the use of those devices. When those mobile phones were cultured they showed positive to gram-negative pathogens. 
These findings show the importance of having a deliberate plan in medical libraries for increasing the information dissemination. In other words, widening the access to library resources should not push the users across the addiction level of mobile phones.

\section{Conclusion}

The survey conducted on the experimental group of students revealed that students can be grouped into four categories based on the applications they use in mobile devices, where the first group is the potential students who use the mobile devices for information retrieval. Since the use of social networks fall within this group, social networks have the potentiality to be used to disseminate medical related information. Students receive medical related information via the Internet and regular communication using mobile devices.

Majority of the students retrieve medical information through web resources and in the personal communication majority of them receive information from friends. Highly used online resources are eBooks, Google, Wikipedia, MedlinePlus. The PubMed is used only by the quarter faction of total students and a very few students use other medical related sources. There are different purposes of retrieving information through mobile devices; among them the highest usage was observed for retrieval of an image, followed by the information on drugs and clinical guidelines. A weak network or signal coverage and slow Internet connectivity are major barriers that indicated by the students for using mobile devices for information retrieval. The third major barrier is the lack of Wi-Fi facilities in university/hospital/hostel.

The qualitative analysis revealed that students have a positive inclination towards the use of mobile devices to access online resources and shows that they prefer these devices for learning purposes over the physical books, especially to prepare themselves when attending the patients. The survey has proved that incorporating mobile devices at faculties and hospitals will enhance the learning activities and improve the diagnosis.

However, they also expressed their concern about the authenticity and reliability of online materials and evaluate the standards of online resources much below the authentic books. One of the major requests is more training and awareness services to introduce to use the mobile devices for effective information retrieval. The barriers, which are temporary and personal, are to be removed with strategies and aids. With certain improvements, the mobile devices are of excellent sources of information for medical students. Fair and wise exploitation of these devices will reap the full benefit of medical information literacy in all medical faculties in Sri Lanka. 


\section{Acknowledgments}

Authors are highly indebted to record their sincere gratitude to the following medical faculty librarians for the timely and considerate helps to gather the information for this experimental study: Mrs. M.P.L.P. Marasinghe, Senior Assistant Librarian, University of Kelaniya; Mrs. C.S. Ranasinghe, Deputy Librarian, University of Sri Jayawardenepura; Mrs.K.Murugadas, Senior Assistant Librarian, University of Jaffna;Mrs. S. Perera, Senior Assistant Librarian, University of Peradeniya; and Mrs. W.M.P.G.K. Thushara Wanasinghe, Senior Assistant Librarian, Rajarata University of Sri Lanka.

\section{Reference}

Alleyne, R. (2011). The young generation are "addicted" to mobile phones. The Telegraph. Retrieved from

https://www.telegraph.co.uk/technology/8458786/The-young-generation-areaddicted-to-mobile-phones.html

De-Arteaga, M., Eggel, I., Do, B., Rubin, D., Kahn, C. E., \& Müller, H. (2015). Comparing image search behaviour in the ARRS GoldMiner search engine and a clinical PACS/RIS. Journal of Biomedical Informatics, 56, 57-64. https://doi.org/10.1016/J.JBI.2015.04.013

Dixit, S., Shukla, H., Bhagwat, A. K., Bindal, A., Goyal, A., Zaidi, A. K., \& Shrivastava, A. (2010). A Study to Evaluate Mobile Phone Dependence Among Students of a Medical College and Associated Hospital of Central India. Indian Journal of Community Medicine : Official Publication of Indian Association of Preventive \& Social Medicine, 35(2), 339-341. https://doi.org/10.4103/0970-0218.66878

Lepp, A., Barkley, J. E., \& Karpinski, A. C. (2014). The relationship between cell phone use, academic performance, anxiety, and Satisfaction with Life in college students. Computers in Human Behavior, 31, 343-350. https://doi.org/https://doi.org/10.1016/j.chb.2013.10.049

Liyanage, L. N. (2015). Usage of mobile phones among university students in Sri Lanka. National Conference on Applied Social Statistics Research (NCASSR), Social Statistics Students' Association, Department of Economics, University of Kelaniya, Sri Lanka. pp 24.

Ramesh, J., Carter, A. O., Campbell, M. H., Gibbons, N., Powlett, C., Moseley Sr, H., ... Carter, T. (2018). Use of mobile phones by medical staff at Queen Elizabeth Hospital, Barbados: evidence for both benefit and harm. Journal of Hospital Infection, 70(2), 160-165. https://doi.org/10.1016/j.jhin.2008.06.007

Taradi, S. K., Taradi, M., Taradi, S. K., \& Taradi, M. (2016). Making physiology learning memorable: a mobile phone-assisted case-based instructional strategy, Advances in Physiology Education 40(3), 383-387.

https://doi.org/10.1152/advan.00187.2015

Verto Analytics. (2017). Mobile, PC or Tablet? Study reveals sectors most dominated by different devices. Retrieved February 10, 2018, from http://www.digitalstrategyconsulting.com/intelligence/2017/06/mobile_pc_or_ tablet_study_reveals_sectors_most_dominated_by_different_devices.php 
Ye, C. (2010). Application and Trend of Mobile Digital Library Services. In Y. Chunqing (Ed.), Proceedings of the 2010 International Conference on Information Technology and Scientific Management, USA: Scientific Research Publishing, pp 170-173. Retrieved from file.scirp.org/pdf/201.49.pdf 